\title{
UN EJEMPLO DE PERIODIZACIÓN: EL TEMPLO DE SAN MARTIÑO DE NOIA
}

\author{
Por \\ BEGOÑA FERNÁNDEZ RODRÍGUEZ
}

En pleno casco histórico de la villa de Noia se levanta el templo de San Martiño, como exponente de una serie de características y postulados que hacen que el edificio se convierta, ya desde época temprana, en uno de los símbolos más significativos de la actual ciudad, y cuya importancia, a pesar de su aparente simplicidad explica que se halle incluido en una serie de obras que con carácter general o concreto analizan el patrimonio artístico'.

Sin embargo, esta inclusión no implica que en torno a este edificio surjan toda una serie de dudas que no encuentran fácil respuesta ya que, al

\footnotetext{
'Entre las obras que se hacen eco del templo noiense se pueden mencionar: MOLINA, F. (Ldo).: Descripción del Reyno de Galicia y de las cosas notables del, con las Armas, y los Blasones de los Linages de Galicia, de donde proceden señaladas casas en Castilla. Ed. facsímil, 1675; LAMPÉREZ Y ROMEA, V.: «San Martín de Noya». Boletín de la Sociedad de Excursiones, $\mathrm{n}^{\circ}$. 126, 128, (1903); VILLAAMIL Y CASTRO, J.: Iglesias gallegas en la Edad Media. Madrid, 1904; LAMPÉREZ Y ROMEA, V.: Historia de la Arquitectura Cristiana Española. T. III. Madrid, 1930; HOYO, J. del.: Memorias del Arzobispado de Santiago. Santiago de Compostela, 1952; CAAMAÑO MARTÍNEZ, J.M.: Contribución al estudio del gótico en Galicia. Valladolid, 1972; MARTÍNEZ MURGUÍA, M.: Galicia. Madrid, 1889 (ed. facsímil de García Beramendi, J) Madrid, 1985; CARRÉ ALDAO, E.: «Provincia de La Coruña». Geografia General del Reino de Galicia, (dir por Carreras Candí, F) La Coruña, 1930. (ed. facsímil, La Coruña, 1987, IV, V, VI, VII); CASTILLO LÓPEZ, Á. del.: Inventario de la riqueza monumental y artística de Galicia. Fundación Pedro Barrié de la Maza, La Coruña, 1987; PÉREZ CONSTANTI, P.: Diccionario de artístas que florecieron en Galicia en los siglos XVI y XVIII. Santiago de Compostela, 1988.
}

"CUADERNOS DE ESTUDIOS GALLEGOS", Tomo XLVII, Fascículo 112, Santiago 2000. 
igual que otros templos medievales gallegos, su levantamiento no fue fruto de una única campaña constructiva, afirmación atestiguada por la presencia de toda una serie de diferentes elementos estructurales, de referentes heráldicos e, incluso, de arrepentimientos presentes que denotan, sin duda, la existencia de más de una fase.

Los escasos datos conocidos con respecto al templo noiense, implican que para los primeros tiempos del edificio sea necesario recurrir a meras hipótesis; tradicionalmente, y tal y como ocurre en otros edificios de carácter religioso de esta misma época, se apunta la posibilidad de la existencia de una fábrica anterior a la actual de San Martiñoº ${ }^{2}$, llegando autores a precisar la cronología de la anterior edificación remontándola por lo menos al siglo XIII ${ }^{3}$.

A pesar de la ausencia en su interior, al margen de los elementos arquitectónicos, de referentes heráldicos o epigráficos que ayuden a aproximarse a su cronología, en su exterior, sí están presentes, por lo que se posibilita la aproximación al conjunto al margen de elementos meramente estilísticos.

Así, en la portada principal de acceso al templo, en el tímpano liso (Figura 1), se ubican tres escudos; el central, de mayor tamaño, se corresponde con las armas de Castilla y León y se halla flanqueado por dos idénticos, organizados con un campo en el que se representa una luna menguante, ajedrezada y adornada con una orla cargada de roeles con esmaltes figurados que se corresponden con las armas delArzobispo compostelano, Don Lope de Mendoza (Figura 2).

No obstante, a pesar de que esta combinación de elementos heráldicos no resulta novedosa por su aparición en otras obras patrocinadas por el

\footnotetext{
${ }^{2}$ Los estudiosos coinciden en señalar que en el solar, que ocupa el templo actual, existió una ermita, a la que la tradición le atribuye la advocación de Santa María, razonando tal hipótesis, en el dato de que la iglesia que construyó el Arzobispo compostelano, Don Berenguel, también en Noia, se le denominó Santa María a Nova, prueba de que hubo otra «vella» y además a San Bartolomé como primer patrón que fue de Noia. CARRÉ ALDAO, E.: «Provincia de La Coruña»... Op. cit., p. 159.

${ }^{3}$ López Ferreiro, considera que no se llevaría a cabo en el siglo XV una nueva construcción, sino que se trataría de una reedificación y engrandecimiento del antiguo templo. LÓPEZ FERREIRO, J.: Historia de la S.A.M. Iglesia de Santiago de Compostela. T. VII, Santiago de Compostela, 1900-1904, p. 67.
}

"CUADERNOS DE ESTUDIOS GALLEGOS", Tomo XLVII, Fascículo 112, Santiago 2000. 


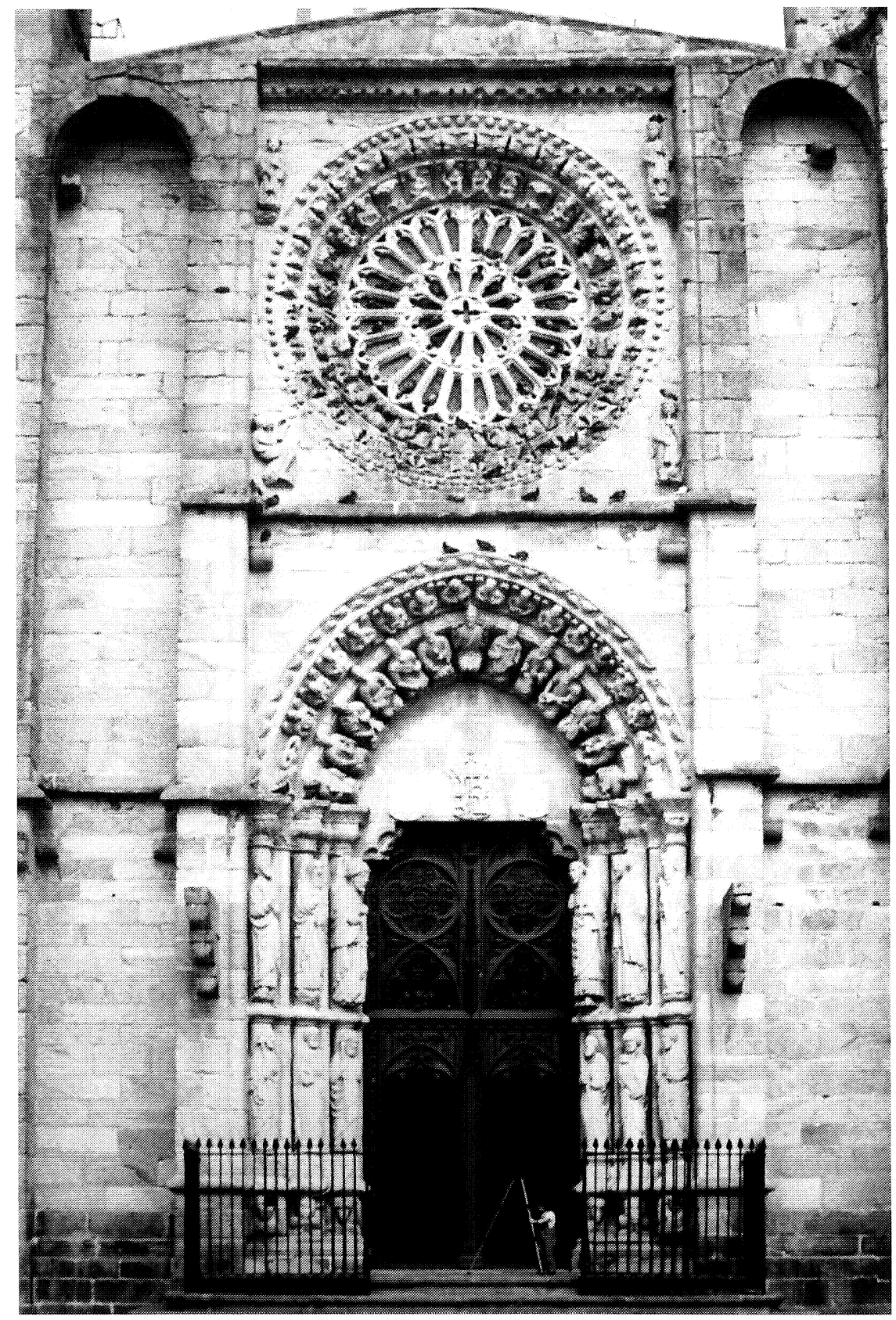

Figura 1. 


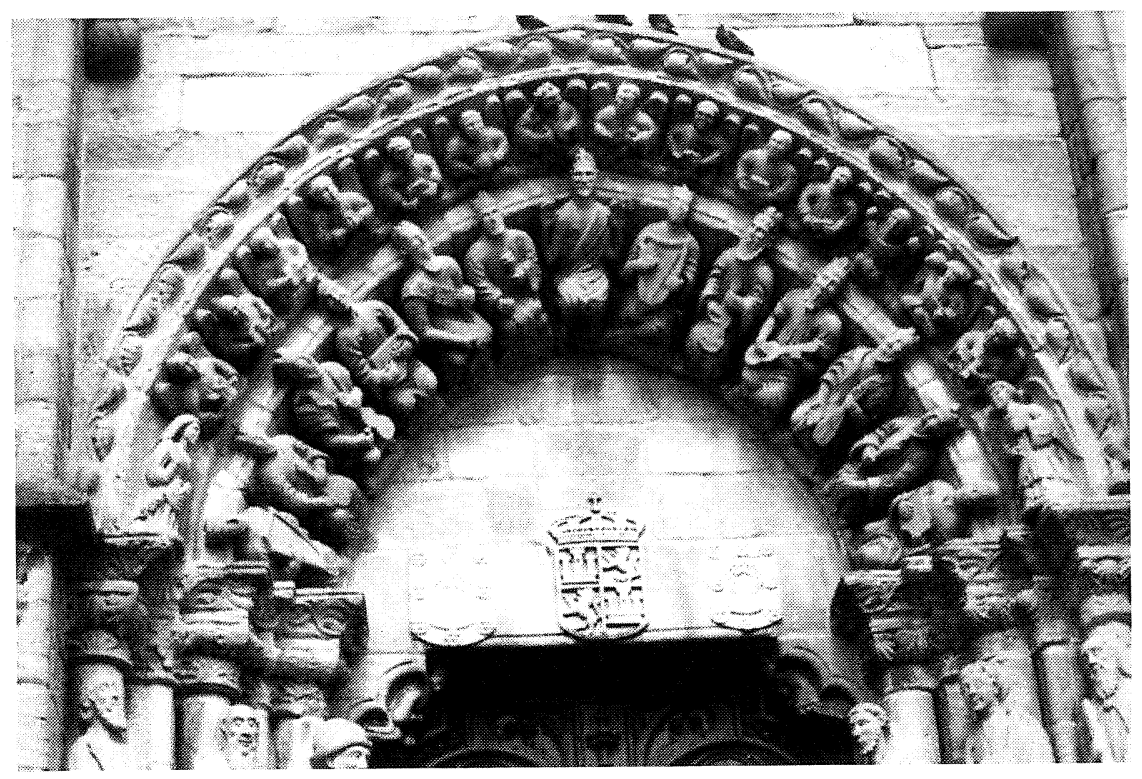

Figura 2.

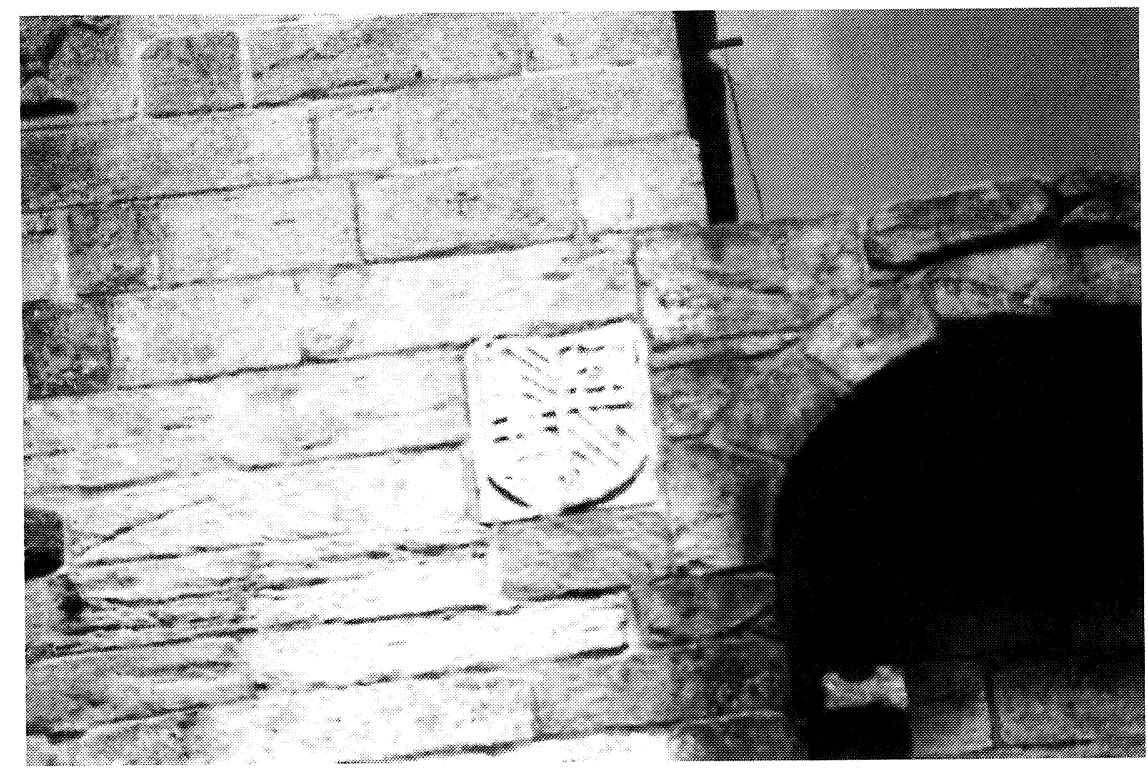

Figura 3. 
Arzobispo santiagués ${ }^{4}$, en el caso del tímpano noiense, es fruto de una reorganización posterior pues, como apunta Caamaño Martínez, el dintel es la única pieza antigua que se conserva en el tímpano, ya que en un fotograbado recogido por Martínez Murguía, se observa la existencia de un vano abierto directamente sobre el dintel ${ }^{5}$.

A pesar de este hecho, este referente heráldico se completa con el aporte epigráfico al disponerse en la parte inferior del dintel una inscripción, que se constituye en un referente directo a la hora de datar la obra, y en exponente de toda una serie de reminiscencias compostelanas, presentes eso sí, en toda la fachada occidental del templo noiense ${ }^{6}$.

La inscripción del templo noiense excesivamente parca no proporciona más que una mera referencia cronológica; así en ella se lee

\section{«ERA: DA: NAC: D: M: CCCCIIII» ${ }^{7}$}

Pero junto a estos dos referentes -heráldico y epigráfico- en los contrafuertes de las torres aparecen sendos emblemas heráldicos que no repiten ninguno de los modelos presentes en el tímpano. El que se encuentra en el lado izquierdo (Figura 3) se compone de un campo cuartelado, figurándose en el primer y cuarto cuartel sobre fondo de plata, cinco cintas o coreas de gules, mientras en el segundo y tercero, sobre un campo de azur,

\footnotetext{
${ }^{4}$ La combinación de las armas del prelado con las de Castilla y León está también presente en una obra financiada por el Arzobispo en Compostela, en concreto en las obras del cimborrio de la Catedral. MANSO PORTO, C.: «A arte Gótica». Arte Medieval, T. II, A Coruña, 1996, p. 359.

${ }^{5}$ CAAMAÑO MARTÍNEZ, J.M.: Contribución al estudio ... Op. cit., p. 214.

${ }^{6}$ No en vano, la inscripción que conmemora el asiento de los dinteles del Pórtico de la Gloria, se ubica en el dintel derecho e izquierdo del propio pórtico. MORALEJO ÁLVAREZ, S.: «El 1 de Abril de 1188. Marco histórico y contexto litúrgico en la obra del Pórtico de la Gloria». Actas del Simposio internacional sobre O Pórtico da Gloria e a Arte do seu tempo. Santiago de Compostela, 1991, p. 19.; tradición ésta que desde la obra catedralicia se irradia también a otros templos de la ciudad compostelana, tal es el caso del de San Fiz de Solovio donde el artista escoge el dintel como el lugar más idóneo para albergar la inscripción. CAAMAÑO MARTÍNEZ, J.M.: «Seis tímpanos compostelanos de la adoración de los reyes». Archivo Español de Arte, nº 12, (1985), pp. 333-336.

${ }^{7}$ CAAMAÑO MARTÍNEZ, J.M.: Contribución al estudio ... Op. cit., pp. 214-215. López Ferreiro, siguiendo a Villaamil y Castro efectúa una lectura distinta de la misma, indicando que esta se leería: ERA: DA NA (scen) ÇA: D (e): MCCCCXXXIIII. LÓPEZ FEREIRO, J.: Historia de la S.A.M. Iglesia de Santiago... Op. cit., p. 67.
}

"CUADERNOS DE ESTUDIOS GALLEGOS", Tomo XLVII, Fascículo 112, Santiago 2000. 
cinco flores de lis de oro dispuestas en sotuer ${ }^{8}$, escudo que se corresponde con el del también Arzobispo compostelano Don Álvaro de Isorna y Mendaña.

El dispuesto sobre el contrafuerte de la derecha (Figura 4), por su parte, no presenta, debido al estado en que se halla, una fácil identificación, pero se cree que al disponer en un campo de plata un manojo de juncos, complementado con una leyenda en caracteres góticos, se corresponde con uno de los cuatro emblemas empleados por los miembros del linaje de los Junqueras ${ }^{9}$, en concreto, con las armas correspondientes a Martín Rodríguez de Junqueras.

Estos tres referentes heráldicos dispuestos en el hastial occidental, llevarían a pensar que el templo se realiza, bajo el patronato de tres personajes: dos arzobispos compostelanos y un miembro de la nobleza gallega.

No cabe duda que las obras se debieron de iniciar bajo el patrocinio de Don Lope de Mendoza, ya que sus escudos figuran en el tímpano y la inscripción de la parte inferior del dintel se corresponde con uno de los años de su mandato al frente de la diócesis compostelana.

Con la llegada a laArchidiócesis del que «Fue el vigésimo sexto arçobispo de Santiago, en tiempo del rey don Juan, el segundo. Eralo el año de quatroçientos y ocho, como consta en la Historia de dicho rey don Juan y debía serlo algunos años antes» ${ }^{10}$, se produce un «replanteamiento» de los endebles equilibrios de fuerzas en Galicia. Su designación fue debida a un procedimiento de urgencia que tenía como fin zanjar la incierta situación creada, a causa del exilio del Arzobispo García Manrique, de ahí que el monarca Enrique III, dada la situación de incertidumbre se viera obligado a reiterar la obligación de hacer pleito de homenaje al nuevo prelado $^{11}$.

${ }^{8}$ CRESPO DEL POZO, J.: Blasones y Linajes del Reino de Galicia. T. III, Poyo, 1965, p. 126.

${ }^{9}$ La nobleza de dicho linaje aparece ya probada en el siglo XII «La antigüedad de la casa cuyos representantes fueron siempre habidos como hidalgos conspicuos sin que tuviesen que demostrar su nobleza en pleito alguno. La casa comenzaría con la figura de Martín Rodríguez de Junqueras, el Viejo, en 1272, destacando los miembros de su linaje por la importancia y la valentía, así como por sus buenas hazañas». Ibídem, pp. 132-134.

${ }^{10}$ HOYO, J.del.: Memorias del Arzobispado ... Op. cit., p. 23.

${ }^{11}$ GARCÍA ORO, J.: Galicia en los siglos XIV y XV. La Coruña, 1987, pp. 137-138. 


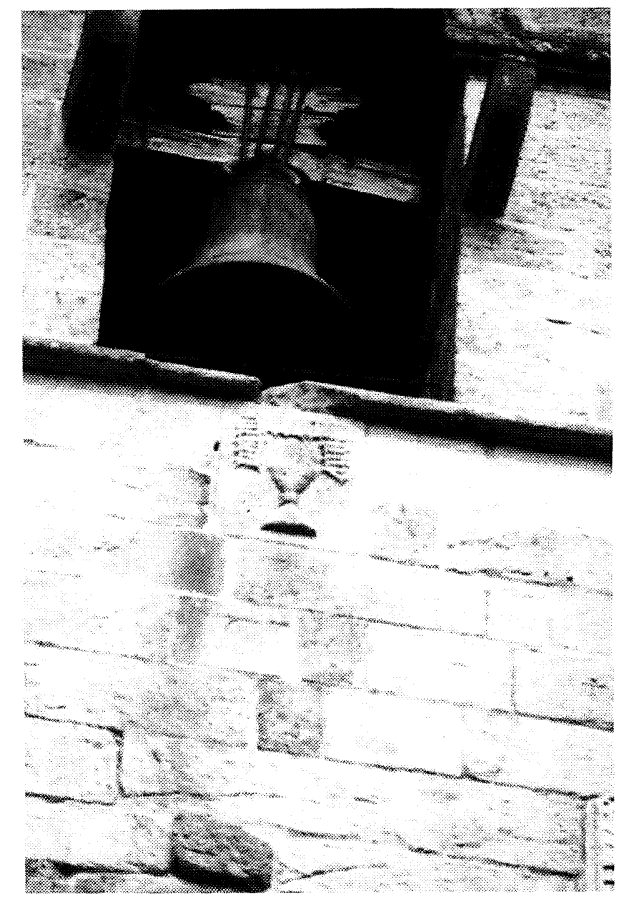

Figura 4.

Éste, de origen sevillano, desarrolló un activo papel político al frente de la archidiócesis compostelana, que dirigió durante un período de cuarenta y cinco años (1400-45) $)^{12}$. Durante su mandato, y a pesar de una serie de problemas iniciales, Noia mantiene una situación de normalidad ligada a los intereses municipales de la Tierra de Santiago ${ }^{13}$.

${ }^{12}$ Anteriormente a esta fecha, Don Lope de Mendoza, quien fue desde muy temprano en su ciudad prebendado, habría ocupado el cargo de obispo de Mondoñedo entre 139399. CAAMAÑO MARTÍNEZ, J.M.: «ElArzobispo compostelano Don Lope de Mendoza $(+1445)$ y sus empresas artísticas». Boletín de la Sociedad de Arte y Arqueología., T. XXVI, (1960), p. 21.

${ }^{13}$ Ello explica que hacia el 1400 , la villa se manifieste ya como el verdadero feudo de los arzobispos compostelanos. El prelado aparte de señor de la villa se convierte en patrono de la iglesia de San Martiño y, en virtud de ello recibe la mitad de todos los bienes, rentas y colaciones que se recogen en el templo parroquial, siendo el mayordomo arzobispal el encargado de recaudar y administrar dichos bienes. GARCÍA ORO, J.: Galicia en los siglos ... Op. cit., pp. 173-174.

"CUADERNOS DE ESTUDIOS GALLEGOS", Tomo XLVII, Fascículo 112, Santiago 2000. 
En Compostela, sin embargo, a pesar de los intentos del arzobispo de mejorar la situación con la concesión de nuevas ordenanzas al concejo, fomentando, así, el régimen municipal al incrementar, a su vez, su papel representativo ${ }^{14}$, el prelado se debió de enfrentar a una situación más conflictiva, ya que todas estas medidas legislativas, necesarias para hacer frente a la presión nobiliaria, no lograron que el Arzobispo consiguiera el apoyo de los núcleos urbanos, al convertirse él en el mayor obstáculo para que las ciudades gozaran de las libertades que sí poseían las de realengo, pretensión que lleva a los compostelanos a establecer la llamada Hermandad, generándose una situación de incertidumbre e inextabilidad que, en junio de 1421, desembocará en un conflicto revolucionario, cuyo levantamiento se organiza aprovechando una ausencia del Arzobispo ${ }^{15}$ quien cuando intenta regresar a la ciudad ve como se le prohibe la entrada ${ }^{16}$.

A pesar de que estos acontecimientos políticos entrañan un cierto componente de crisis, no encuentran el mismo reflejo en el mundo cultural. Durante los cuarenta y cinco años que Don Lope permanece al frente de la Diócesis compostelana desarrolla una importante labor como patrono de empresas artísticas, tanto en construcciones de carácter civil como religioso, ya que al hacerse cargo de obras de importante magnitud, Don Lope se convierte en el reflejo del hombre de su tiempo y cortesano: "Asaz gracioso y de dulce conversación, muy bien garnido en su persona y casa

${ }^{14}$ Esta política de incentivar la representatividad municipal, afectó a numerosas villas de la tierra de Santiago entre las que se halla Noia, a la que según una carta fechada en Valladolid el doce de Mayo de 1428, el Arzobispo otorgaba ordenanzas idénticas a las concedidas, años antes, a la villa de Muros: derecho de elección de dos representantes por parte de los moradores mayores y sus oficios y un representante de la comunidad y de los pescadores para que éstos, juntamente con el procurador del concejo y los jurados, intervengan en los repartimientos, y en la división de las rentas». CAAMAÑO MARTÍNEZ, J.M.: «El Arzobispo Don Lope ... « Op. cit., p. 27.

${ }^{15} \mathrm{El}$ movimiento, que tiene su origen en Compostela reivindicaba entre otros aspectos el deseo de obtener del monarca «cartas para no satisfacer los tributos que siempre habrían satisfecho al Arzobispo a rebelarse contra el prelado y a negarle obediencia que le debían». Ibídem, p. 28.

${ }^{16}$ Los sucesos de la rebelión se conoeen gracias la conservación del Memorial que el Arzobispo Don Lope y los miembros del cabildo de Santiago dirigen al pontífice Martín $V$ haciendo hincapié, sobre todo, tanto el arzobispo como los capitulares en las infracciones de carácter religioso que habían infringido los rebeldes. LÓPEZ FERREIRO, J.: Historia de la S.A.M. ... Op. cit., pp. 37-38.

"CUADERNOS DE ESTUDIOS GALLEGOS", Tomo XLVII, Fascículo 112, Santiago 2000. 
que tenía magnificamente su estado ansi en su capilla como en su cámara e mesa y vestiase muy preciosamente ansi que en guarniciones y arreos ningún Prelado de su tiempo se igualo a él’ ${ }^{17}$ que busca, al desarrollar su mecenazgo, dejar constancia de la obstentación de su poder ${ }^{18}$.

Dentro de las construcciones de carácter civil destaca su intervención en el llamado Castillo de la Rocha Blanca ${ }^{19}$ a la vez que, en la propia ciudad de Santiago, donde llevará a cabo labores de remodelación urbanística y de control en las calles adyacentes al recinto catedralicio ${ }^{20}$.

Por su parte, dentro de las construcciones de carácter religioso, hay que resaltar tanto las emprendidas en la ciudad compostelana, como fuera de ésta. Dentro del primer grupo, destaca la actividad desarrollada en el recinto catedralicio, donde el Arzobispo realiza su propia capilla funeraria $^{21}$ y las obras de remodelación del cimborrio, en sustitución de la estructura primitiva ${ }^{22}$.

Correspondientes al segundo grupo, es decir, fuera de la ciudad compostelana, el Arzobispo centra su actividad en las tres villas más importantes de la Tierra de Santiago, donde todavía se constata su impronta. En

${ }^{17}$ PÉREZ DE GÚZMAN, F.: Generaciones y semblanzas. Cap. XVIII cit. Ibídem, p. 38.

${ }^{18}$ CAAMAÑO MARTíNEZ, J.M.: «El Arzobispo Don Lope de Mendoza ... « Op. cit., p. 30

${ }^{19}$ Éste no fue edificado «ad fundamentis» por el prelado, quien llevó a cabo una serie de obras de reforma; sin embargo, debido al escaso número de restos que se conservan, casi exclusivamente de carácter decorativo, no pueden avalar el carácter de las obras de reforma emprendidas por el Arzobispo. Ibídem, p. 32.

${ }^{20}$ Sobre las actuaciones llevadas a cabo en las calles adyacentes al recinto catedralicio véase, LÓPEZ FERREIRO, J.: Historia de la S.A.M. .... Op. cit., pp. 74-80.

${ }^{21}$ Esta obra está considerada como la empresa artística más importante emprendida por el Arzobispo compostelano; iniciada en 1442 se remata en 1451, cuando éste ya había fallecido, por su pariente el Cardenal Martín López. Aunque, en la actualidad como consecuencia de las reformas del siglo XVIII, la capilla ha desaparecido, ésta se abría a la nave lateral en el lado del Evangelio, en el solar en el que actualmente se emplaza la llamada capilla de la Comunión y en la que se albergaba el sepulcro del arzobispo y algunos enterramientos familiares. MANSO PORTO, C.: «A arte Gótica» ... Op. cit., pp. 360-361.

${ }^{22}$ Aunque actualmente éste se halla muy reformado debido a los añadidos realizados en la época barroca, que han modificado tanto su estructura interior como exterior, en función de la inscripción conservada en uno de sus vanos, esta obra se data, tal como apunta Manso Porto, entorno a 1422. MANSO PORTO, C.: «A arte Gótica» ... Op. cit., p. 359. En la actualidad se conoce la organización gracias a un dibujo conservado. LÓPEZ FERREIRO, J.: Historia de la S.A.M. ... Op. cit., rep. 202-203.

"CUADERNOS DE ESTUDIOS GALLEGOS", Tomo XLVII, Fascículo 112, Santiago 2000. 
Padrón, Don Lope realiza una reforma en la iglesia parroquial de Santia$\mathrm{go}^{23}$, en Muros, ordena la reedificación del templo de Santa María del $\mathrm{Campo}^{24}$, y a su munificencia se debe también en Noia, la iglesia de San Martíño ${ }^{25}$, obra que no fue financiada exclusivamente, tal y como apuntan algunos historiadores ya a principios del siglo, por Don Lope; así, Villaamil y Castro, al respecto del templo noiense, indica: «Tampoco admite duda que la hermosa iglesia parroquial de San Martín de la villa de Noya, una de las más notables construcciones ojivales levantadas en Galicia, sea debida al Arzobispo Don Lope sino toda ella, la rica fachada principal con su portada profusamente decorada de estatuas $\rangle^{26}$.

Otro de los patrocinadores del templo noiense, tal y como se atestigua por el aporte heráldico existente en su fachada, será el sucesor de Don Lope de Mendoza al frente de la curia compostelana: Don Álvaro de Isorna y Mendaña, quien «fue vigesimo septimo arçobispo de Santiago y primero había sido obispo de Mondoñedo y de Cuenca y de aquí paso a Santiago. Fue elegido el primero de nobiembre año de mill quatroçientos quarenta e çinco. Murió a nuebe-1449-y su cuerpo está en la capilla de los raçioneros de Sancto Spiritus. Dexo a la dignidad arçobispal las tierras de Camba y Rodeiro $\rangle^{27}$.

Por su parte, López Ferreiro completa los conocimientos sobre este arzobispo, indicando algunos datos biográficos ${ }^{28}$; su estancia al frente de la Archidiócesis comprendió un período muy corto -cuatro años-y ha sido considerado por García Oro como «una etapa de interregno o sede vacante en la que todo cabe y todo es posible $»^{29}$, que contrasta con los

${ }^{23}$ CAAMAÑo MARTíNEZ, J.M.: «El Arzobispo Don Lope de Mendoza ....» Op. cit., p. 48.

${ }^{24}$ En esta iglesia, al igual que sucede en Noia se atestigua su patronato con la presencia de toda una serie de signos heráldicos y epigráficos, que recuerdan la labor del Arzobispo en la citada construcción.

${ }^{25}$ CAAMAÑO MARTÍNEZ, J.M.: «El Arzobispo Don Lope de Mendoza ....» Op. cit., p. 48.

${ }^{26}$ VILLAAMIL y CASTRO, J.: Galicia Diplomática. T. V, (1896), p. 95.

${ }^{27}$ HOYO, J.del.: Memorias del Arzobispado ... Op. cit., p. 23.

${ }^{28}$ Hijo de Núñez de Isorna y de Doña Constanza Vázquez de Insua, hija de Vasco Pérez Vamonde y nieto de Nuño Pérez de Isorna, había nacido, en Santiago de Foz, cerca de Mondoñedo, sito en el lugar de Pazo de Quintans, parroquia de Santa María de Isorna. LÓPEZ FERREIRO, J.: Historia de la S.A.M. ... Op. cit., p. 169

${ }^{29}$ GARCÍA ORO, J.: Galicia en los siglos XIV y XV ... Op. cit., pp. 140-141.

"CUADERnOS DE ESTUdios GALLEGOS", Tomo XLVII, Fascículo 112, Santiago 2000. 
sucesos acaecidos en la diócesis en los obispados que le precedieron y le sucedieron. Pero si por algo se puede caracterizar su mandato es por conseguir el logro de una perpetua y cordial armonía con el clero ${ }^{30}$.

Pero junto a estos dos emblemas heráldicos de arzobispos compostelanos en su hastial se conserva también el de un miembro de la clase nobiliaria: Don Martín Rodríguez de Junqueras; éste guardaría una estrecha relación con el Arzobispo Álvaro de Isorna al ser considerado como su sobrino $^{31}$, siendo un personaje del que no se conoce un excesivo número de datos ${ }^{32}$.

${ }^{30}$ En la información proporcionada por López Ferreiro hay abundantes testimonios al respecto; así a modo de ejemplo se puede citar, el suceso acaecido en 1446, cuando el Cabildo expresa al Arzobispo su deseo de arrendar a Juan de Lisboa los cotos de Ribaderoa en Portugal cuyos beneficios pertenecían a la mesa arzobispal y a la capitular, por lo que se solicita autorización al prelado que se encontraba en Noia, para que su intención fuera aprobada a lo que el Arzobispo responde «Ben sabedes que nosso estilo en semellantes cousas a nos he ynoto, que nunca nos elo acaecemos ... en esto poede nosa diligencia honesta et boa se faça o que os ditos señores nos scripuiron et para nos abtoridade para elo damos noso poder complido a o arcediano de Salnes». LÓPEZ FERREIRO, J.: Historia de la S.A.M. ... Op. cit., p. 177.

${ }^{31}$ En 1418, el Arzobispo lega a Martín Rodríguez de Junqueras el coto de Vilar de Alón, cerca del castillo de Jallas, el de Verdeogas, con su pazo, tierras y señorios, así como el derecho de presentar varios curatos. CRESPO DEL POZO, J.: Blasones y Linajes ... Op. cit., p. 133.

${ }^{32}$ De este caballero se desconoce tanto la fecha de nacimiento como la de defunción. No obstante, se tiene constancia de que en 1418 , se hallaba vivo, al igual que en 1485 , fecha en que cede a su hijo Esteban de Junqueras el foro que poseía en San Xusto de Toxosoutos. Este caballero contrae matrimonio con Inés de Sotomayor, con lo que el señor de Junqueras se vincula a la estirpe más importante del sur de Galicia y de cuyo matrimonio nacerá uno de los personajes más importantes de la Galicia del siglo XV: su hijo Esteban de Junqueras. Ibídem, pp. 133-134. Se desconoce donde se hallan enterrados los restos de este caballero, aunque si se tiene constancia de que tanto su esposa como su hijo fueron inhumados en el convento franciscano de San Antonio de la Puebla, aunque actualmente los cenotafios de los Junqueras se hallan ubicados en la capilla del Pazo de Oca, donde fueron trasladados por miembros de la familia Camarasa. FERNÁNDEZ RODRÍGUEZ, B.: La iglesia parroquial de Santiago de la Puebla del Deán y la influencia de la «nueva devotio». Tesis de licenciatura inédita. Santiago de Compostela, 1993. p. 83. Información que contrasta con el dato que apuntan algunos historiadores, al reseñar que el Señor de Junqueras al morir sin descendencia, y ser nombrado heredero del Arzobispo compostelano los bienes heredados de éste serían reintegrados a la diócesis. Véase MANSO PORTO, C.: «El códice medieval del Convento de Santo Domingo de Santiago». Archivo Dominicano T. III y VII, (1982-1986), p. 96, nota ${ }^{\circ} 20$.

"CUADERNOS DE ESTUDIOS GALLEGOS", Tomo XLVII, Fascículo 112, Santiago 2000. 
Las referencias heráldicas del exterior del templo, no se reducen exclusivamente a las dispuestas en su fachada occidental. Así, en el tercer paramento mural del lado del Evangelio, en las proximidades de la puerta de acceso lateral al templo, se encuentra un escudo que nuevamente alude al prelado compostelano Don Lope de Mendoza, lo que hace que se atestigue su participación en este lienzo mural ${ }^{33}$.

Todos estos emblemas heráldicos del exterior referidos tanto a los Arzobispos Don Lope de Mendoza (1440-1445), y Don Álvaro de Isorna (1445-1449), como a su heredero Don Martín Rodríguez de Junqueras, (1418-1485), atestiguan su participación en el exterior de la obra.

Por el contrario, en el interior del conjunto la ausencia total de elementos tanto epigráficos como heráldicos, hace que sea necesario para proceder a su datación recurrir a los elementos propiamente formales, siempre teniendo presente que éstos, en parte, pierden valor cronológico, ya que al desarrollarse a partir de una fuente común -las innovaciones de la arquitectura mendicante- $\mathrm{y}$ dada su amplia difusión, se convierten, en referentes nulos a la hora de abordar un aspecto cronológico concreto. De ahí que los datos referenciales ubicados en la fachada y en el paramento mural del lado del Evangelio, valgan a la hora de encuadrar el templo en un espacio cronológico concreto, convirtiéndose la fecha de 1434 en el único referente cronológico preciso para el templo ${ }^{34}$.

Interiormente, el templo (Figura 5), que se caracteriza por una gran sencillez espacial, responde dentro de la clasificación de Caamaño Martí-

\footnotetext{
${ }^{33}$ La posible participación del Arzobispo compostelano en el templo noiense, aparece también constatada por la figura orante que se representa en el tímpano de la portada lateral. Ésta, dispuesta en el lado izquierdo, ataviada con una indumentaria -capa pluvial, mitra y báculo- que lo identifica como miembro de la jerarquía eclesiástica, ha sido relacionado tradicionalmente con una representación de Don Lope de Mendoza. CAAMAÑO MARTÍNEZ, J.M.: Contribución al estudio ... Op. cit., p. 218. Representación que no supone novedad iconográfica, ya que la presencia de los comitentes en las obras que patrocinan, responde a las pautas artísticas de una corriente que ya se halla presente desde el siglo XIII, cuando el monarca se empieza a representar en las obras que él patrocina. Sobre el tema, véase NÚÑEZ RODRÍGUEZ, M.: «El rey, la catedral y la expresión de un programa». Espacio Tiempo y Forma. Serie VII, nº 5, (1992), pp. 27-51.

${ }^{34} \mathrm{El}$ hecho de que Abellá apunte que la fundación del templo por el Arzobispo Don Lope de Mendoza se produce en 1474, se cree que pueda tratarse de un error de lectura del epígrafe del dintel, ya que el arzobispo compostelano fallece el tres de febrero de 1445. ABELLA, S.: La Villa de Noya, su historia, su topografia y sus monumentos. Buenos Aires, 1911, p. 15.
}

"CUADERNOS DE ESTUDIOS GALLEGOS", Tomo XLVII, Fascículo 112, Santiago 2000. 


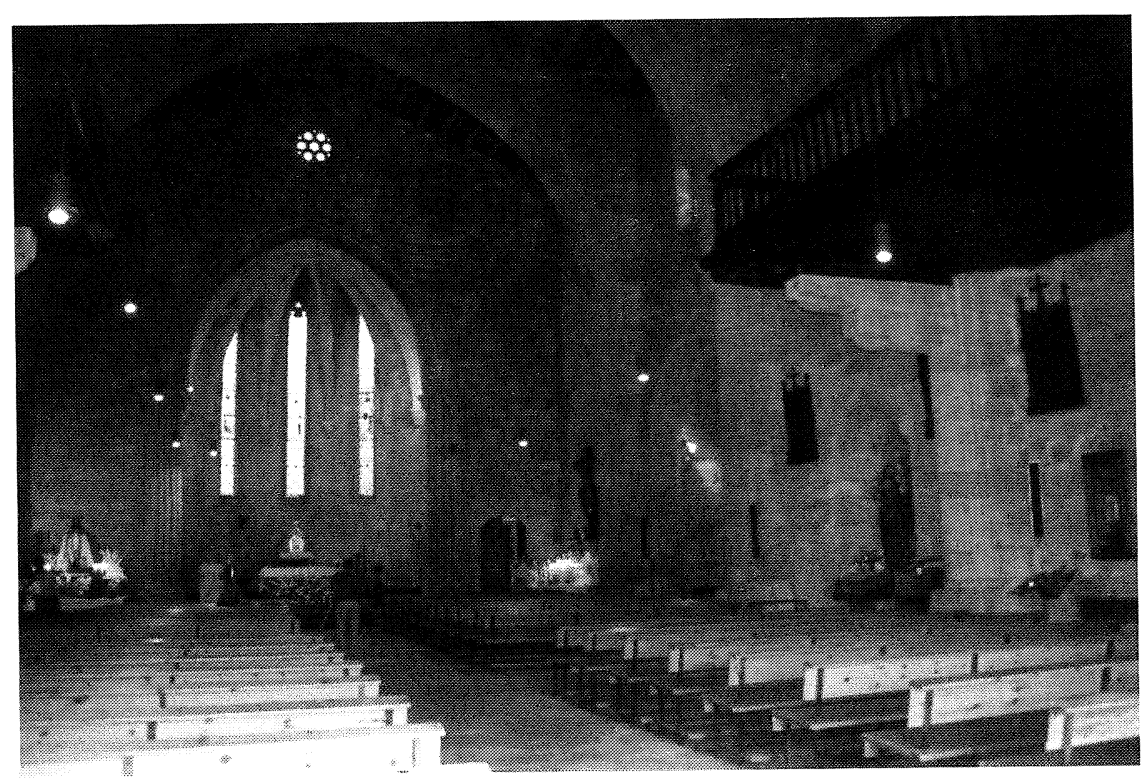

Figura 5.

nez para los templos góticos gallegos, al tipo de una nave y capilla mayor poligonal ${ }^{35}$. Ésta se estructura en cinco tramos organizados por cuatro arcos de carácter apuntado, doblados y de perfil rectangular, sobre los que descansa una cubierta de madera a doble vertiente organizada a base de pares y coreas $^{36}$, presentando en uno de sus lados, en concreto en el se-

${ }^{35}$ Tipología que tiene su origen en un carácter autóctono, al tener un claro precedente en los templos románicos gallegos, y estableciendo similitudes con los templos mendicantes, en concreto con las iglesias de las órdenes femeninas, aunque con ellas también se detecten diferencias. Sin embargo, en su génesis también habrá de tenerse en cuenta la existencia de vinculaciones con construcciones navarras desarrolladas ya desde el siglo XII, marcadas por los rasgos característicos del regionalismo y con su génesis fuertemente enraizada en el mundo galo, o las establecidas con aquellas construcciones que siguen las pautas del mudejar andaluz, o incluso con las construcciones castellanas, muy vinculadas al igual que las obras gallegas a los templos mendicantes femeninos. CAAMAÑO MARTÍNEZ, J.M.: Contribución al estudio ... Op. cit., p. 19.

${ }^{36}$ A pesar de esta organización la cubierta se corresponde con una estructura moderna, que sustituye a la primitiva, en la que también estaría presente esta misma organización. LAMPÉREZ Y ROMEA, V.: Historia de la arquitectura ... Op. cit., p. 159.

"CUADERNOS DE ESTUDIOS GALLEGOS", Tomo XLVII, Fascículo 112, Santiago 2000. 
gundo tramo del lado de la Epístola, una capilla de planta cuadrangular, abierta a la nave por medio de un arco de medio punto conocida como Capilla de los Valderrama y que se corresponde con una realización de finales del siglo XVI o principios del siglo XVII ${ }^{37}$.

No obstante, el hecho de que los cuatro arcos que organizan el espacio de la nave, no respondan a un mismo esquema lleva a plantear la posibilidad de que la organización de éste no sea fruto de una única fase constructiva, dato que podría explicar el empleo de arcos diferenciados entre los dos primeros tramos de la nave y los dos últimos, a pesar de que todos ellos, como se indicó, respondan a un mismo modelo estructural.

En los últimos tramos de la nave (Figura 6), el espacio se organiza con un tipo de arco en el que la decoración se halla totalmente ausente, solamente por medio de una nacela se achaflanan sus esquinas, moldura que es, así, la encargada de suavizar la arista generada. La sección de éstos se encuentra presente también en otros templos gallegos coetáneos, bien adscritos a las órdenes mendicantes, como puede ser San Francisco de A Coruña, Santo Domingo de Ribadavia o a instituciones monásticas como San Salvador de Cines e, incluso a simples parroquiales

\footnotetext{
${ }^{37}$ Ésta fue realizada bajo la advocación de la Encarnación y de San Juan Bautista y levantada por contrato establecido entre Fernando Romero Dacosta, quien ocupa el cargo de «regidor de la dicha villa», y Mateo de Cubas «maestro de canteria», haciéndolo el primero por «deseo de dar cumplimiento a las últimas voluntades de su tío Gabriel Freire, clérigo de San Mamed do Monte, tal y como se recoge, en una de las cláusulas testamentarias de 1598: "es mi voluntad que mi heredero y cumplidor que yo nombrase luego que yo falleciese traten con el consistorio y Reximiento de la villa de Noia y con las más personas que poder e | facultad tengan den acceso y consentimiento para que el dicho mi heredero a costa de mis bienes haga facer una capilla de l cinco clavos de grano en la iglesia de San Martiño de la dicha villa en el altar del Señor San Juan y la haga y perfeccione hasta acabarla y ponerla en perfección para decir misa y ahi trasladar los huesos de mi padre, madre, mios en la dicha capilla y de los demás de mis deudos que a mi heredero le pareciere». NÚÑEZ RODRÍGUEZ, M.: «Mateo de Cubas y la capilla de los Valderrama (San Martín de Noya)». Jubilatio, Homenaje de la Facultad de Geografía e Historia a Don Manuel Lucas Álvarez y Don Ángel Rodríguez González. Santiago de Compostela, 1987, pp. 621-622; sin embargo a pesar de esta cronología y por diversos problemas, Mateo de Cubas no emprenderá la construcción de la misma hasta la segunda década del siglo XVII, tal y como se atestigua por un documento de 1610 , donde es requerido por Fernando Romero Dacosta, alegando haberle dado más dinero para la capilla que estaba obligado a realizar en San Martiño de Noia. PÉREZ CONSTANTI, P.: Diccionario de artistas ... Op. cit., p. 144.
}

"CUADERNOS DE ESTUDIOS GALLEGOS", Tomo XLVII, Fascículo 112, Santiago 2000. 


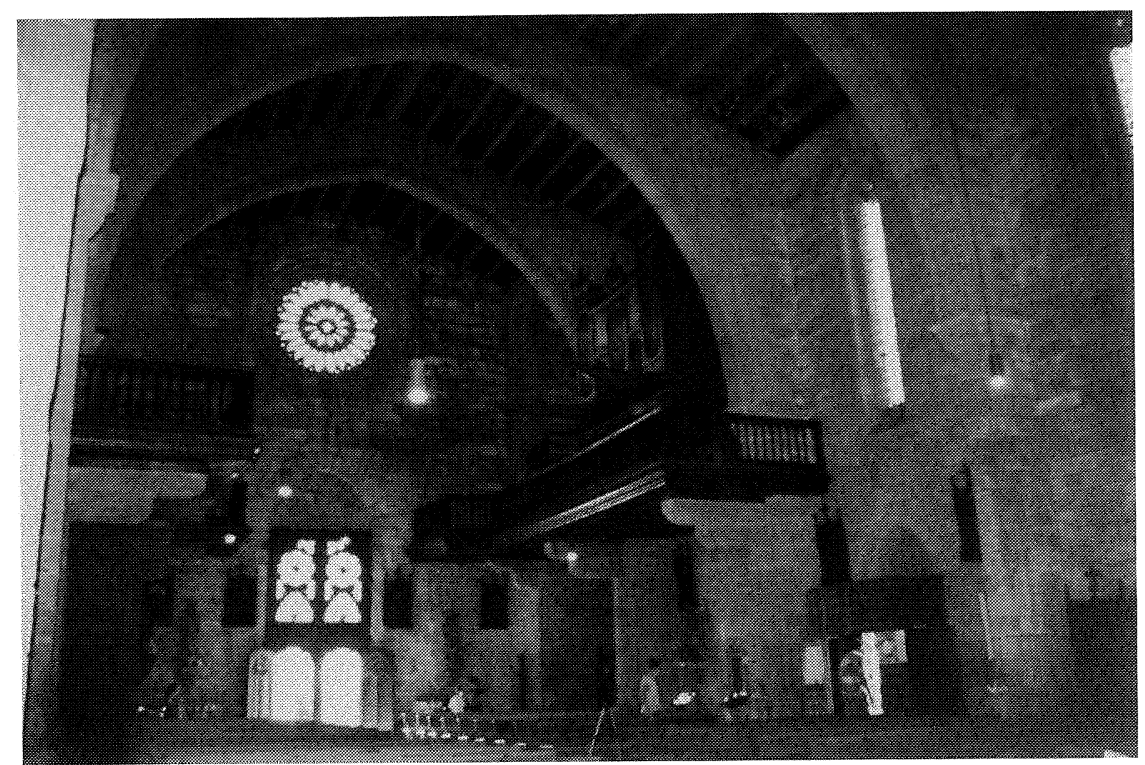

Figura 6.

como en Santa María del Campo de Muros ${ }^{38}$, o las de Betanzos ${ }^{39}$, tanto Santa María deAzougue como Santiago, a pesar de que en estas últimas se produzcan pequeñas variaciones con respecto a los que articulan San Martiño, al disponerse en los ángulos en vez de molduras en nacela, cortes en chaflan, que, al igual que en el caso anterior, suavizan la arista generada.

Los dos arcos que configuran el espacio de la nave más próximo a la cabecera (Figura 7), poseen un mayor enriquecimiento decorativo, no solo dispuesto en la dobladura del arco sino también extendido a toda su rosca y que se caracteriza por el empleo en el cierre de baquetones. La proliferación de molduras no presenta, sin embargo, en este periodo un carácter

${ }^{38}$ Este templo parroquial presenta con el ejemplo noiense más de un punto de conexión, ya que como indica Caamaño Martínez ambas se deben al patronato de Don Lope de Mendoza. Al respecto véase CAAMAÑO MARTÍNEZ, J.M.: «El Arzobispo Don Lope de Mendoza ...» Op. cit.

${ }^{39}$ C.O.A.G.: Arquitectura Gótica en Galicia. Los templos: catálogo gráfico. Santiago de Compostela, 1986, p. 18.

"CUADERNOS DE ESTUDIOS GALLEGOS", Tomo XLVII, Fascículo 112, Santiago 2000. 
recurrente en arcos de perfíl rectangular sino que su empleo será más frecuente en los de sección triangular ${ }^{40}$.

No obstante, entre estas dos molduras se disponen frisos con motivos vegetales, tanto en su dobladura como en su rosca. Motivo decorativo que encuentra su fuente de inspiración en obras de la ciudad compostelana; en concreto, en la Catedral de Santiago, donde el motivo se vincula con la obra que el Maestro Mateo realiza en el Pórtico de la Gloria, en la que los arcos, también baquetonados, se decoran en sus nervios, con motivos vegetales realizados con importante volumen, en los que sobresale el elemento central ${ }^{41}$.

Este motivo goza de importante difusión, así en el Palacio de Gelmírez, en el llamado Salón Sinodal, obra del siglo XIII en la que interviene Pedro Bouth ${ }^{42}$, en concreto en la cabecera y en los primeros tramos del mismo se disponen, aunque con menor volumen que los mateínos, estos elementos decorativos que ocupan, ya no solamente la dobladura del arco sino también las roscas ${ }^{43}$.

No obstante, en Santiago, su presencia se detecta también en otros templos, tal es el caso de Santo Domingo de Bonaval, donde su existencia se constata tanto en los arcos de la bóveda de la capilla mayor como en los de ingreso a la misma, realizaciones que Manso Porto vincula con soluciones catedralicias tanto ourensanas como compostelanas ${ }^{44}$.

A pesar de esta posible conexión compostelana que es altamente viable, teniendo presente los paralelos existentes en el templo de Noia con realizaciones santiaguesas, y que se constituyen en claro ejemplo de lo

\footnotetext{
${ }^{40}$ Ibídem, p. 18.

${ }^{41}$ YZQUIERDO PERRÍN, R.: «El protogótico». La Catedral de Santiago de Compostela, Serie Catedrales, A Coruña, 1990.

${ }^{42}$ CHAMOSO LAMAS, M.: «Arte». Galicia. Barcelona, 1976, p. 265

${ }^{43}$ Sobre el refectorio del Palacio de Gelmirez véase NÚÑ̃Z RODRÍGUEZ, M.: El refectorio del Palacio de Gelmirez. El espejo moral de un espacio para el yantar. Santiago de Compostela, 1996.

${ }^{44}$ Para la Catedral santiaguesa, la autora constata ya su presencia en las metopas de la portada de Platerias, o en su interior, en la portada conocida como Tímpano de la Batalla de Clavijo, datadas, al igual que las realizaciones del Palacio Arzobispal durante el Arzobispado de Don Juan Arias. No obstante, esta misma autora señala como el motivo también se halla presente en la rosca interna de las arquerias de la Claustra Nova ourensana, o en varios relieves de su alzado. MANSO PORTO, C.: Arte gótico en Galicia: los Dominicos. La Coruña, 1993, p. 168.
} 


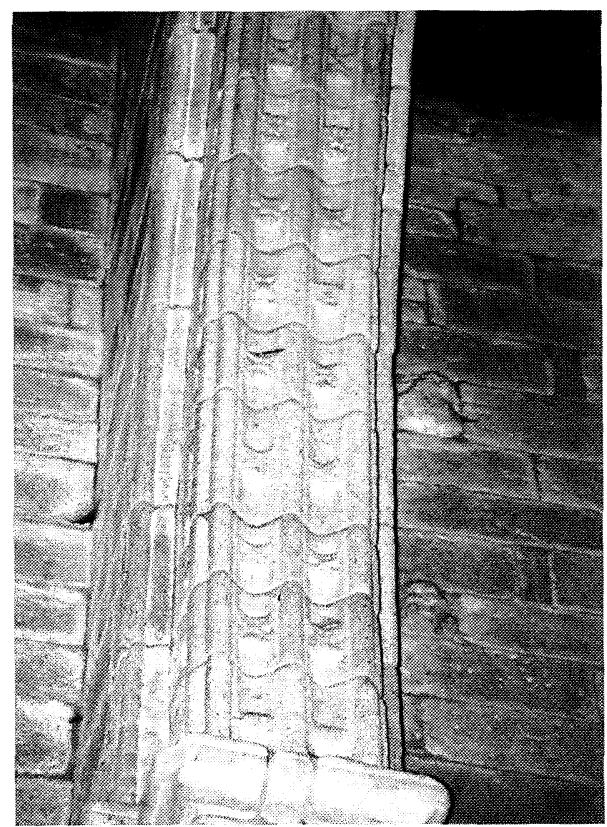

Figura 7.

que ha sido definido por Moralejo Álvarez como renacimiento mateíno, característico del arte gallego desde el último tercio del siglo XIV a la primera mitad del $\mathrm{XV}^{45}$, hay también que señalar que este motivo vegetal, debido a su carácter plano, podría establecer conexión con otros que aparecen en templos dominicos del sur de la provincia de Pontevedra ${ }^{46}$.

${ }^{45}$ En el arte gallego hasta la primera mitad del siglo XIV, no se producen más que citas aisladas que tienen como referencia los motivos desarrollados por Mateo en su obra y que deben ser entendidos como los comienzos de un retorno que se consuma a finales del siglo XIV y en la mitad del XV, hecho éste que lleva a eliminar el término de pervivencia para acuñar este autor el de renacimiento, ya que al evocar en los presupuestos, como indica el autor «no lo determina tanto el que el arte mateíno constituyerá la presunta plamación de un genio nacional como otra vez el vacío, la falta de tradición que obliga a vivir sobre el terreno a recurrir a todo lo que se tiene a mano». MORALEJO ÁLVAREZ, S.: Escultura Gótica en Galicia, (1200-1350). Resumen de Tesis Doctoral, Santiago de Compostela, 1975, p. 26.

${ }^{46}$ Motivos de estas mismas características aparecen en el templo de Santo Domingo de Tui, en concreto decorando la rosca de la portada de acceso al claustro y a la sala capitular. MANSO PORTO, C.: Arte gótico en Galicia ... Op. cit., pp. 350-351.

"CUADERNOS DE ESTUDIOS GALLEGOS", Tomo XLVII, Fascículo 112, Santiago 2000. 
Este mismo motivo decorativo aparece igualmente en el arco de ingreso al presbiterio del conjunto noiense, mientras en la dobladura se mantiene la decoración de los dos primeros arcos de la nave, en la rosca se produce un cambio, al introducir un nuevo elemento decorativo constituído por un friso a base de arquillos (Figura 8), carácter diferenciador que enriquece notablemente el acceso al presbiterio.

Sin embargo, éste tampoco resulta novedoso, pues ya se halla presente en portadas de acceso a templos mendicantes de la Diócesis santiaguesa, tales como la Portada sur de San Francisco de Betanzos ${ }^{47}$ a pesar de esta presencia, su origen, ampliamente difundido en Galicia en la época gótica, ha de ser puesto en relación con el denominado por Manso Porto taller lucense $\mathrm{II}^{48}$, cuya presencia se atestigua en la mayoría de los templos existentes en la propia ciudad de Lugo $^{49}$, o en otros de la diócesis mindoniense $\mathrm{e}^{50}$.

${ }^{47}$ A pesar de su presencia en la portada del templo brigantino, en esta tampoco se genera el modelo, sino que se constituye en reflejo de la irradiación del motivo desde otros templos. CAAMAÑO MARTÍNEZ, J.M.: Contribución al estudio ... Op. cit., pp. 144-145; FRAGA SAMPEDRO, M ${ }^{\mathrm{a}}$.D.: Arquitectura de los frailes menores conventuales en la Edad Media gallega (S. XIII-XV). Santiago de Compostela, 1995, p. 173.

${ }^{48}$ Taller que junto con el denominado Lucense I se forma en la obra de la Catedral de Lugo, donde desarrollan su labor en las realizaciones promovidas por Fray Pedro López de Aguiar, en torno a 1380. MANSO PORTO, C.: Arte gótico en Galicia ... Op. cit., p. 102.

${ }^{49}$ Así, en San Francisco de Lugo se encuentra el mismo motivo que en el templo noiense, en los arcosolios de la capilla absidial del lado del Evangelio, e incluso en los abiertos en el tercer tramo del muro sur de la nave. PÉREZ MARTÍNEZ, M.: «Arquitectura mendicante en Galicia: el ejemplo de San Francisco de Lugo». Estudios Mindonienses., $\mathrm{n}^{\circ} 12,(1996), \mathrm{p} .181$. Igualmente, el motivo también se halla presente en el templo dominico de Lugo, en la portada y donde se constata la presencia del segundo taller lucense trabajando en la capilla absidial de la Epístola, entre 1375-1380. MANSO PORTO, C.: Arte Gótico en Galicia ... Op. cit., p. 102.

${ }^{50}$ En estos templos participa un grupo de artífices que si bien forman parte del denominado taller lucense II, eran considerados como el colectivo menos cualificado dentro del mismo, y que llegado un momento, tal vez, de crisis, se excinden del propio taller. Este colectivo desarrolla, con posterioridad, su actividad en templos de menor relevancia $\mathrm{y}$, por norma general, de carácter parroquial, tales como la Iglesia de Santiago de Baamonde, San Pantaleón de Cabanas, o San Pedro de Riobarba. MANSO PORTO, C.: «A arte Gótica»... Op. cit., p. 316.

"CUADERNOS DE ESTUDIOS GALLEGOS", Tomo XLVII, Fascículo 112, Santiago 2000. 


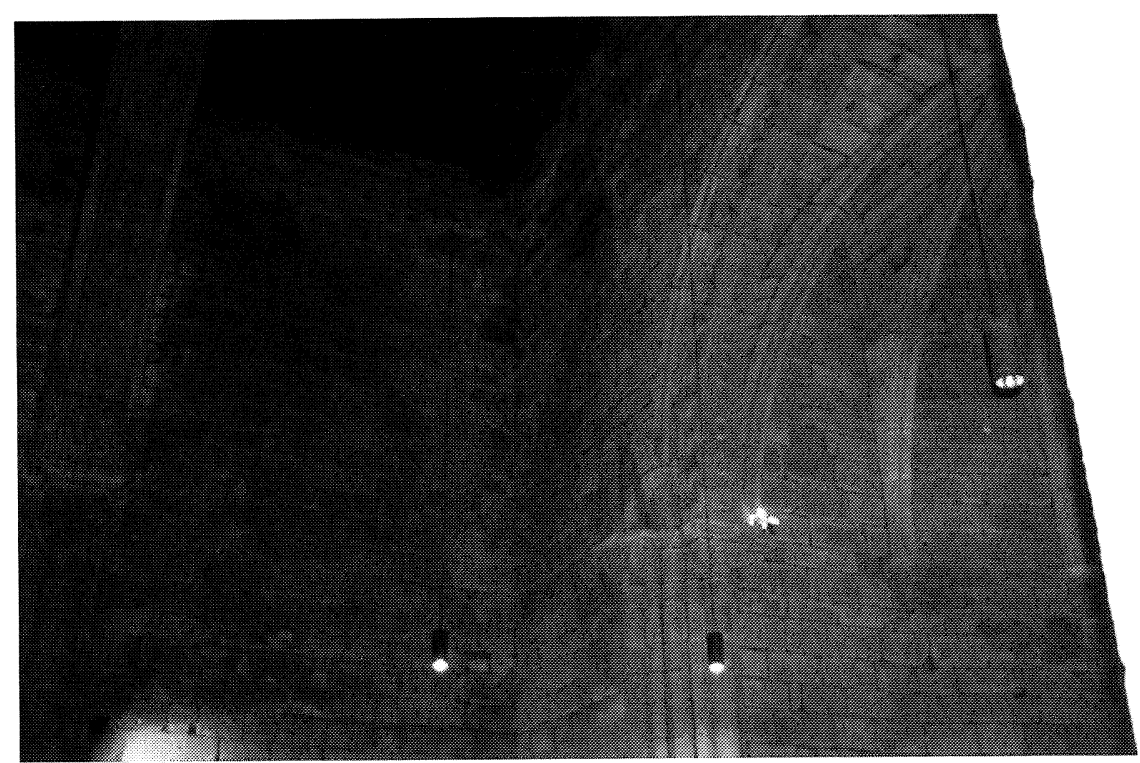

Figura 8.

Pero junto al empleo de estos arcos diferenciados en su interior existe otro indicio que resulta significativo para la hipótesis de que el templo no fue construído en una única etapa o de que hubo en el momento de su ejecución un cambio de traza con respecto al modelo con que fue concebido. Así, en el muro del testero de la nave, junto al arco de cierre de la capilla mayor, se disponen dos arranques de arco, testigos, sin duda, de la intencionalidad de organizar este espacio con un sistema de tres naves, en lugar de la única actual, estructura que no se llegó a concretar, tal y como apuntan la mayoría de los historiadores ${ }^{51}$.

${ }^{51}$ Ya Lampérez y Romea plantea la posibilidad de la existencia de las tres naves que, sin embargo, reduce la idea a una mera hipótesis. Así apunta: «A la derecha y la izquierda del arco de triunfo hay pilares adosados con arranques de arcos. ¿Iba a tener tres naves?, el caso no sería único (Santiago de La Coruña sería otro...) pero es muy dudoso pues el ancho de la nave no da para la tridivisión; más entonces no se explica la presencia de aquellos pilares. LAMPÉREZ y ROMEA, V.: Historia de la arquitectura española cristiana. T. III, Madrid, 1933, p. 157. Por su parte Caamaño Martínez recoge también dicha propuesta. CAAMAÑO MARTÍNEZ, J.M.: «El Arzobispo Don Lope... «Op. cit., p. 60.

"CUADERNOS DE ESTUDIOS GALLEGOS", Tomo XLVII, Fascículo 112, Santiago 2000. 
Este arrepentimiento arquitectónico nos pone también en relación con otro de los aspectos interesantes a la hora de abordar la periodización del templo noiense: el sentido constructivo seguido para edificar la obra que, como ya se ha indicado, dadas las diferencias todavía hoy apreciables sería fruto de dos grandes fases constructivas.

Caamaño Martínez, sostiene al respecto, que el templo en su proceso edificatorio se vió condicionado por la existencia en el mismo recinto de un templo primitivo, lo que lleva a que la nueva obra, siempre según este autor, edificada en una única fase, se comenzase por el hastial occidental $^{52}$ y no por su cabecera, de ahí que la inscripción presente en el dintel de la puerta de acceso haga referencia a la fecha en que ésta se concluye ${ }^{53}$.

A la labor del Arzobispo Don Lope en el hastial occidental se debe igualmente añadir que bajo، su mandato se debió de ejecutar también el cierre de los muros del inmueble, tal y como se atestigua por la presencia del escudo del prelado compostelano en el tercer paramento mural del lado norte. Sin embargo, ¿qué se realiza en el interior durante su mandato?. Responder a este interrogante, dada la ausencia de referentes resulta complejo, no obstante aquí las obras se debieron de realizar en sentido contrario, emprendiendo el prelado compostelano probablemente la capilla mayor y el cierre de los dos primeros tramos de la nave, que presentan una continuidad estructural y decorativa, quedando su labor inconclusa en los dos últimos, ya que si se hubieran realizado, como apunta Caamaño Martínez, en una única fase, el templo gozaría de un principio de homogeneidad que se haya ausente, como se analizó, en el espacio de la nave.

Todos estos aspectos se complementan con el arrepentimiento arquitectónico presente en el testero de la nave ya que éste, probablemente realizado bajo el patrocinio de Don Lope, encuentra su explicación en el sentido constructivo arriba mencionado, es decir, una vez rematado el perímetro y cerrado su capilla mayor se decide la organización del espacio interno en tres naves, para lo cual se procedió a realizar los soportes y el arranque de los arcos formeros, que mantendrían la misma decoración

${ }^{52}$ Este autor con la excepción de la tribuna que interpreta como una realización de finales del siglo XV o principios del XVI, atribuye íntegramente la obra al mecenazgo de Don Lope de Mendoza. Ibídem, p. 68.

${ }^{53}$ Ibídem, p. 68.

"CUADERnOS DE ESTUdios GALLEGOS", Tomo XLVII, Fascículo 112, Santiago 2000. 
y estructura que los que articulan los primeros tramos de la nave, proyecto que fue abandonado, bien por problemas económicos o bien por falta de espacio para la división tripartita, organizándose todo el espacio en una única nave, y quedando relegado el cierre de los dos últimos tramos al patrocinio de su sucesor, el también Arzobispo Don Álvaro de Isorna y de su heredero, el Señor de Junqueras, Don Martín Rodríguez de Junqueras, proceso que explicaría que sus referentes heráldicos figuren en los contrafuertes del hastial occidental. 